\title{
Fasting Might Not Be Necessary Before Lipid Screening: A Nationally Representative Cross-sectional Study
}

AUTHORS: Michael J. Steiner, MD, Asheley Cockrell Skinner, PhD, and Eliana M. Perrin, MD, MPH

Division of General Pediatrics and Adolescent Medicine, Department of Pediatrics, School of Medicine, University of North Carolina, Chapel Hill, North Carolina

\section{KEY WORDS}

cholesterol, fasting

\section{ABBREVIATIONS}

AAP—American Academy of Pediatrics

TC- - total cholesterol

$\mathrm{HDL}$-high-density lipoprotein

LDL-low-density lipoprotein

VLDL—very low-density lipoprotein

NHANES - National Health and Nutrition Examination Survey

Drs Steiner, Perrin, and Skinner all made substantial contributions to the conception and design of the study and interpretation of the data; Dr Skinner acquired and analyzed all of the data; Dr Steiner drafted the manuscript; and all authors contributed to ongoing revision of the manuscript. All authors have approved the article for submission and publication.

www.pediatrics.org/cgi/doi/10.1542/peds.2011-0844

doi:10.1542/peds.2011-0844

Accepted for publication May 13, 2011

Address correspondence to Michael J. Steiner, MD, CB 7600, 101 Manning Dr, Chapel Hill, NC 27599. E-mail: msteiner@med.unc. edu

PEDIATRICS (ISSN Numbers: Print, 0031-4005; Online, 1098-4275). Copyright (C) 2011 by the American Academy of Pediatrics FINANCIAL DISCLOSURE: The authors have indicated they have no financial relationships relevant to this article to disclose.

Funded by the National Institutes of Health (NIH).

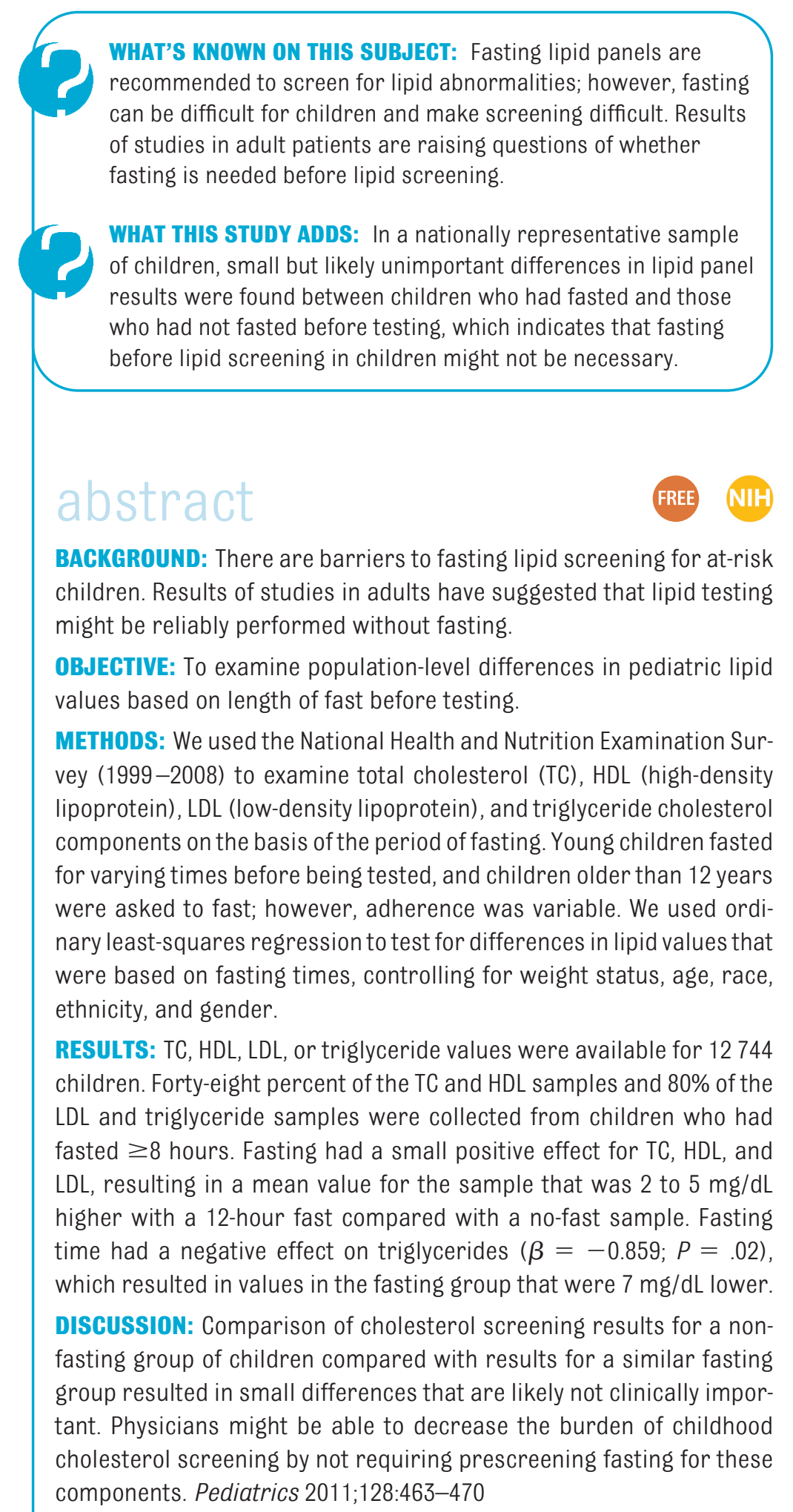


There is heightened concern about the current and future cardiovascular health of children and adolescents. The high prevalence of obesity, ${ }^{1}$ the recognition that hyperlipidemia in childhood has an immediate impact and might have a long- term impact on cardiovascular physiology, ${ }^{2-4}$ and the increasing number of treatment options for hyperlipidemia in children ${ }^{5,6}$ have all led the American Academy of Pediatrics (AAP) and the American Heart Association to recommend fasting lipid panel screening for children as young as 2 years who are at risk for dyslipidemia. ${ }^{6,7}$

Screening of children for lipid disorders presents unique challenges. Most children will not have fasted before a routine physician office visit. 8,9 Therefore, most fasting lipid panels must be either planned before visits or checked at subsequent office visits or additional visits to outpatient phlebotomy centers. These arrangements require many parents to miss work and children to miss school to arrive for an early morning test, and enforcing the requirement that children fast might be more difficult and unpleasant than asking adults to fast. All of these barriers to fasting in children might decrease physician and parental adherence to lipid screening guidelines in children.

Fasting of 8 to 12 hours is recommended before lipid screening because of the theoretical dynamic changes that can occur in test results for some lipid components during a postprandial test. ${ }^{10}$ Cholesterol travels in the blood in 5 major forms: lowdensity lipoproteins (LDLs), intermediate density lipoproteins, high-density lipoproteins (HDLs), very low-density lipoproteins (VLDLs), and chylomicrons. 9,10 Chylomicrons, which are found after intestinal cells absorb fatcontaining food, and VLDL comprise the majority of the serum triglyceride values, and therefore triglycerides change in response to fasting status. ${ }^{9,10}$ In most clinical laboratories, the total cholesterol (TC), HDL, and triglyceride levels in standard lipid panels are directly measured, and the LDL is estimated by use of the Friedewald calculation $(\mathrm{LDL}=[\mathrm{TC}-\mathrm{HDL}]-$ [triglycerides/5]). ${ }^{11}$ Since triglycerides vary according to fasting status, calculated LDL is also affected. ${ }^{12,13}$ Because of the potential impact of eating on triglyceride and LDL values, nonfasting lipid testing is often used only for measuring TC, HDL, and the difference between the 2, or non-HDL cholesterol.

Despite the physiologic explanation of lipid changes related to fasting status, results of recent research in adults and children have raised questions regarding the importance of fasting before the measurement. Researchers have suggested that for the majority of people who take in an average-size meal, the overall lipid profiles will have minimal postprandial change. ${ }^{12,14,15}$ In addition, some research in adult patients has suggested that abnormal postprandial triglyceride levels might actually be more highly associated with cardiovascular disease than abnormal fasting levels. ${ }^{16,17}$ Finally, in reports of studies of both adults and children, various authors have questioned the added value of cardiovascular risk assessment of LDL cholesterol levels beyond TC, HDL, and non-HDL cholesterol levels. ${ }^{18-22}$

Because of the added burden of fasting before screening and the emerging research data that call into question the value of fasting before lipid assessment of cardiovascular risk in adults, we sought to determine the effect of fasting on complete lipid panels in children. Specifically, we took advantage of variable fasting times within the nationally representative National Health and Nutrition Survey (NHANES) to determine if there are differences in $\mathrm{TC}$,
HDL, LDL, and non-HDL cholesterol between blood samples from fasting and nonfasting study participants. Second, if there were important differences, we sought to understand how these varied on the basis of length of fast and the underlying weight status and the gender of the children. Finally, we sought to determine if differences in cholesterol values based on fasting status would lead to changes in classification or differences in treatment options. We hypothesized that there would be differences in triglyceride values that were based on fasting status, but that subsequent difference in the calculated LDL value would actually be minimal, and likely not great enough to cause a change in interpretation of screening results.

\section{PATIENTS AND METHODS}

In this cross-sectional study we took advantage of the natural experimental conditions resulting from the variable fasting times in children before laboratory testing in the NHANES 1999-2008 surveys. The NHANES is a stratified, multistage probability sample of the civilian, noninstitutionalized population of the United States. The data-collection process includes computer-based interviews, an in-home questionnaire on a variety of demographic and health topics, an examination including a thorough physical examination with measured heights and weights, and laboratory measures. $^{23}$

\section{Sample}

We included children aged 3 to 17 years who had at least 1 of the 4 common lipid measurements available (TC, HDL, LDL, or triglycerides).

\section{Independent Variables}

\section{Fasting Time}

All children aged 3 years and older were eligible for lipid testing and were evaluated in either a morning or after- 
noon session. Children evaluated in the morning had TC, HDL, LDL, and triglycerides measured; those aged 12 years or older were asked to fast, whereas those younger than 12 years were given no specific fasting instructions. Children evaluated in the afternoon had TC and HDL measured and were not given any specific fasting instructions regardless of age. Information on time since last food or drink consumed was recorded and available on all children, regardless of session time or specific instructions. We extracted fasting time as reported for each child, and by taking advantage of the different fasting instructions and variable adherence to those instructions, we examined the relationship between fasting time and lipid values.

\section{Weight Status}

We used height and weight as measured during the examination component to calculate BMI and determine percentiles by using a SAS code developed for that purpose (SAS Institute, Cary, NC). ${ }^{24}$

\section{Dependent Variables}

Equipment used for lipid analyses varied according to year. During 19992004, a Roche Hitachi 704 Analyzer (Roche Diagnostics, Fishers, IN) was used; during 2005, a Roche Hitachi 717 was used; during 2006 a Roche Hitachi 912 was used; and during 2007-2008, a Roche Modular P was used. ${ }^{25}$

TC was measured enzymatically in serum or plasma for all years.

HDL cholesterol in 1999-2002 was measured by using heparin-manganese precipitation or direct immunoassay measurement, depending on sample size and patient age. Beginning in 2003, all samples were tested by using a direct immunoassay. Despite the difference in laboratory methods, the changes for HDL values over the period, compared with those for the Centers for Disease
Control reference standard were within the acceptable range, and did not necessitate additional adjustment with our focus on fasting-based differences averaged over the period. ${ }^{25}$

Triglycerides were measured enzymatically in serum for all years.

LDL was calculated from TC, HDL, and triglycerides as follows: $\mathrm{LDL}=(\mathrm{TC}-$ HDL) - (triglycerides/5).

Non-HDL cholesterol was calculated by subtracting the HDL cholesterol value from the TC value.

\section{Statistical Methods}

We first used ordinary least-squares regression to test for differences in lipid values based on fasting times. We controlled for weight status, race, ethnicity, gender, and, because lipid values differ by age, ${ }^{26}$ we also controlled for age, as well as squared and cubic transformations of age. We used these equations to predict lipid values based on fasting time, and graphed mean lipid values across hours of fasting.

Second, we used seemingly unrelated regression models to examine if the effect of fasting time on lipid values varied on the basis of whether the child was healthy weight or overweight/ obese. Healthy weight was defined as $<85$ th percentile, and overweight and obese were collapsed at $\geq 85$ th percentile for all children.

Finally, using our adjusted equations and baseline distribution of cholesterol results in the sample, we calculated predicted lipid values for groups of children from the population who had blood drawn immediately postprandially instead of subsequent to an ideal 12-hour fast.

All analyses were adjusted for the complex survey design of the NHANES and were performed by using the survey estimation routines in Stata 11.0 (Stata Corp, College Station, TX). This study was deemed exempt from insti- tutional review board review (under federal regulation 45 CFR §46.101), because it included the use of only deidentified secondary data.

\section{RESULTS}

A total of 12744 children aged 3 to 17 years had values for at least 1 of the 4 lipid components. The mean age was 11 years, most of the children were healthy weight (64\%), and the fewest children were in the age range of 3 to 5 years because starting in 2006 the NHANES measured lipid values only for children older than 5 years. Triglycerides and LDL results from morning blood tests were available for $38.6 \%$ and $37.5 \%$ of the sample, respectively, and with the use of AAP cutoffs, measured values were normal for $63 \%$ of TC values, $95 \%$ of HDL, $79 \%$ of LDL, and $97 \%$ of triglyceride values. Nearly half (48\%) of the TC and HDL samples were obtained from children who had fasted for at least 8 hours, and $80 \%$ of the LDL and triglyceride sample was from children who had fasted for at least 8 hours (Table 1).

The data in Table 2 demonstrate the mean difference in each lipid component measurement per hour of fasting status. After adjustment for subject age, weight status, self-identified race/ ethnicity, and gender, there were only small changes in lipid components based on hours of fasting, although values for all measurands except nonHDL cholesterol did reach statistical significance. For example, for each hour of fasting, the TC increased by an average of $0.17 \mathrm{mg} / \mathrm{dL}(P=.05)$. Stated another way, if an average child were screened immediately postprandially, his or her TC would be $\sim 2 \mathrm{mg} / \mathrm{dL}$ lower than another average child after a 12hour fast. These results are displayed graphically in Fig 1. The peak mean cholesterol values appear at fasting times of $\sim 5$ and 14 hours, with a minimum value at $\sim 10$ hours of fasting. 
TABLE 1 Demographic and Mean Characteristics $(N=12744)$

\begin{tabular}{|c|c|}
\hline Variable & Value \\
\hline \multicolumn{2}{|l|}{ Gender, \% } \\
\hline Female & 48.3 \\
\hline Male & 51.7 \\
\hline \multicolumn{2}{|l|}{ Race/ethnicity, \% } \\
\hline White & 59.6 \\
\hline Black & 14.9 \\
\hline Hispanic & 19.3 \\
\hline Other race & 6.2 \\
\hline Age, mean (range), y & $11.02(3-17)$ \\
\hline $3-5 y, \%$ & 9.4 \\
\hline $6-8 y, \%$ & 20.5 \\
\hline $9-11$ y, \% & 22.0 \\
\hline $12-14$ y, \% & 23.8 \\
\hline $15-17 y, \%$ & 24.3 \\
\hline \multicolumn{2}{|l|}{ Weight status (percentile), \% } \\
\hline Very obese (>99th) & 4.0 \\
\hline Obese (95th-99th) & 13.1 \\
\hline Overweight (85th-95th) & 15.8 \\
\hline Healthy weight (5th-85th) & 63.7 \\
\hline Underweight (<5th) & 3.4 \\
\hline $\begin{array}{l}\text { Total cholesterol, mean } \\
\text { (range), } \mathrm{mg} / \mathrm{dL}\end{array}$ & $162.2(62-575)$ \\
\hline Normal & 63.4 \\
\hline Borderline & 27.7 \\
\hline High & 8.9 \\
\hline $\mathrm{HDL}$, mean (range), mg/dL & $51.8(16-131)$ \\
\hline Normal & 94.7 \\
\hline Low & 5.3 \\
\hline Non-HDL & $110.4(0-521)$ \\
\hline LDL, mean (range), mg/dL & $91.9(19-311)$ \\
\hline Normal & 79.1 \\
\hline Borderline & 13.9 \\
\hline High & 7.1 \\
\hline $\begin{array}{l}\text { Triglycerides, mean (range), } \\
\qquad \mathrm{mg} / \mathrm{dL}\end{array}$ & $88.4(15-1750)$ \\
\hline Normal & 96.7 \\
\hline High & 3.3 \\
\hline $\begin{array}{l}\text { Total fasting time, mean } \\
\text { (range), } \mathrm{h}\end{array}$ & $6.9(0-180)$ \\
\hline
\end{tabular}

The LDL cholesterol increased in the adjusted model by $0.46 \mathrm{mg} / \mathrm{dL}$ per hour of fasting (Table 2). Again, the LDL of an average child would be $\sim 5 \mathrm{mg} / \mathrm{dL}$ lower immediately postprandially compared with the LDL subsequent to a 12-hour fast. Figure 2 displays the

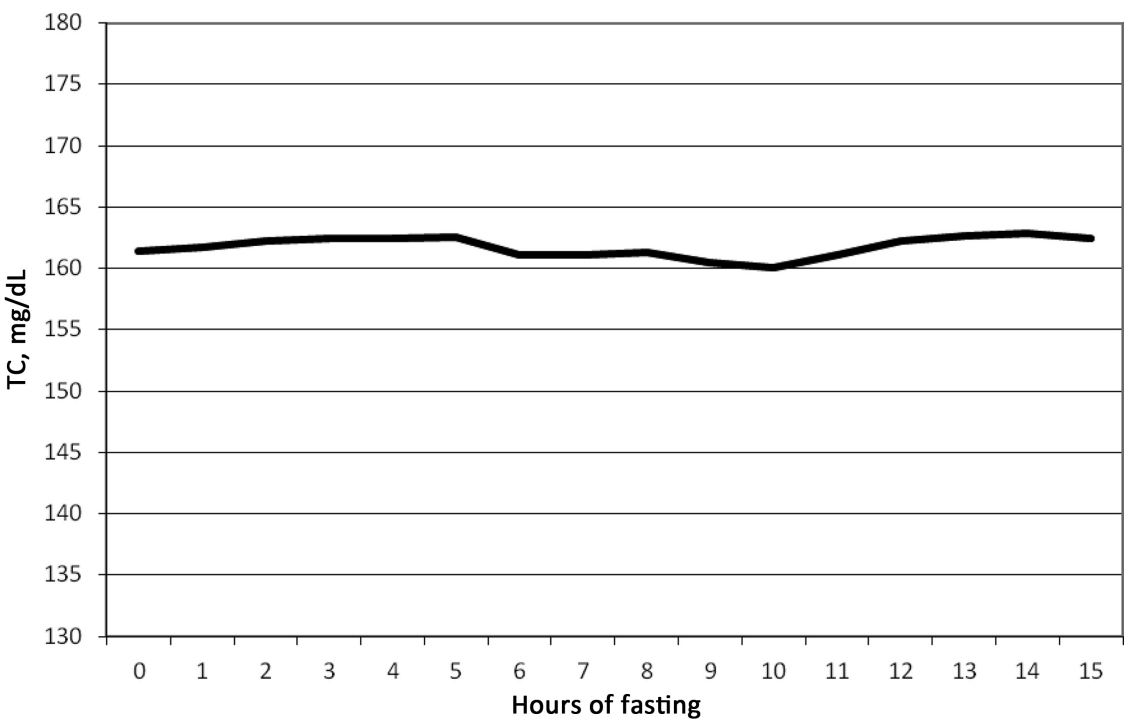

FIGURE 1

Predicted values of TC based on hours of fasting before testing. averaged LDL cholesterol values in children who had fasted for varying amounts of time. This line has a generally linear increase over time that peaks at 15 hours of fasting. The calculated LDL change graphed over time seems to be the inverse of the triglyceride graph, which decreases in a linear fashion over time. The HDL cholesterol increases by an average of 0.08 $\mathrm{mg} / \mathrm{dL}$ per hour (Fig 3). The graph of the HDL cholesterol over time does not demonstrate clinically important change, and because the TC is also relatively stable, the calculated non-HDL cholesterol does not show a dramatic change over time (Fig 3).

Overweight children had slightly increased mean changes in lipid components per hour of fasting compared
TABLE 2 Ordinary Least-Squares Regression of the Effect of Number of Hours (Continuous) on Total Cholesterol, HDL, LDL, and Triglycerides, Unadjusted and Adjusted for Age, Race, Gender, and Weight

\begin{tabular}{lcccccc}
\hline & $\begin{array}{c}\text { Unadjusted } \\
\text { Coefficient }\end{array}$ & $P$ & $\begin{array}{c}\text { 95\% Confidence } \\
\text { Interval }\end{array}$ & $\begin{array}{c}\text { Adjusted } \\
\text { Coefficient }\end{array}$ & $P$ & $\begin{array}{c}95 \% \text { Confidence } \\
\text { Interval }\end{array}$ \\
\hline Cholesterol & 0.033 & .669 & -0.120 to 0.186 & $0.174^{\mathrm{a}}$ & $.048^{\mathrm{a}}$ & 0.002 to $0.346^{\mathrm{a}}$ \\
HDL & 0.034 & .179 & -0.016 to 0.085 & $0.078^{\mathrm{a}}$ & $.007^{\mathrm{a}}$ & 0.022 to $0.133^{\mathrm{a}}$ \\
Non-HDL & -0.001 & .992 & -0.156 to 0.154 & 0.097 & .271 & -0.077 to 0.270 \\
LDL & 0.243 & .115 & -0.061 to 0.548 & $0.456^{\mathrm{a}}$ & $.013^{\mathrm{a}}$ & 0.099 to $0.813^{\mathrm{a}}$ \\
Triglycerides & $-0.664^{\mathrm{a}}$ & $.022^{\mathrm{a}}$ & -1.229 to $-0.100^{\mathrm{a}}$ & $-0.859^{\mathrm{a}}$ & $.019^{\mathrm{a}}$ & -1.573 to $-0.144^{\mathrm{a}}$ \\
\hline a Statistically siónificant effects. & & & & &
\end{tabular}

\section{Effect of Fasting on Lipid Classification}

For TC, nonfasting screening inappropriately classifies $\sim 1 \%$ of children as normal, who would have had borderline values with fasting. In addition, $\sim 1 \%$ of children with borderline nonfasting values would actually have elevated results if fasting. For $L D L, 1.2 \%$ of children with borderline fasting levels would have normal results postprandially, and $1.6 \%$ of children with increased calculated LDL while fasting, would now be considered to have borderline results. For triglycerides, $\sim 4 \%$ of the children classified with normal triglycerides when fasting would have elevated values postprandially. 

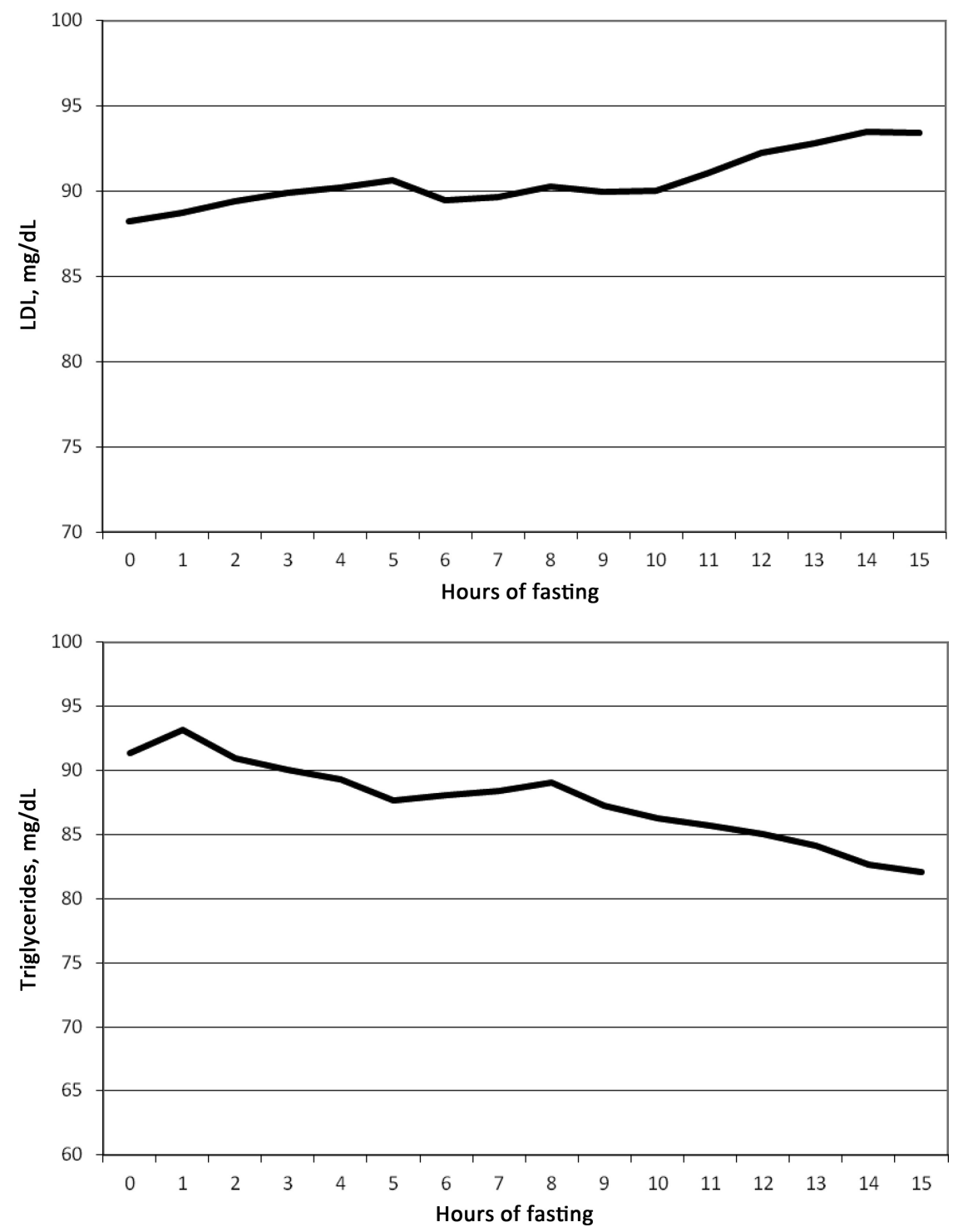

FIGURE 2

Predicted values of LDL cholesterol and triglycerides based on hours of fasting before testing.

\section{DISCUSSION}

Comparing a nationally representative cross-section of children who had fasted for various lengths of time, we demonstrated that nonfasting measurements of TC, calculated LDL, and HDL cholesterol values had only small differences from fasting values. Although statistically significant, these differences are unlikely to result in important clinical changes in the results of screening for cholesterol abnormalities. Triglyceride values differed more dramatically on the basis of fasting status. The weight status and age of subjects within the sample did not consistently affect the variation based on fasting status.

Previous studies in adult patients have also documented minimal differences in lipoprotein profiles after normal food intake in the general population. ${ }^{12}$ In fact, a recent study by Langsted et al in adults found that when LDL samples were corrected for the hemodilution that occurred with fasting while unsweetened fluid intake was allowed, directly measured LDL did not change with fasting. ${ }^{14}$ The differences of cho- lesterol values in our sample based on fasting status are actually smaller than other causes of variation not accounted for in the current screening guidelines. A recent study revealed large variations in fasting LDL cholesterol over time in children. ${ }^{27}$ These differences could cause clinically important changes in diagnosis and treatment. For example, up to 1 in 3 children with elevated LDL levels at 10 years of age will have normal-range levels 3 years later. ${ }^{27}$ The changes in cholesterol values over time have also been studied in relation to retesting of adult patients with normal and abnormal baseline cholesterol values. In these subjects, coefficients of variation for results of retests within a person over time ranged between $6 \%$ and $11 \%$ for the various cholesterol components. ${ }^{28,29}$ For adult patients with elevated TC, this would result in individual variation with an SD of between 15 and $23 \mathrm{mg} / \mathrm{dL} .{ }^{29}$ Although the testing procedure we used was different, and the variation in our study was across a sample instead of within a person, the change in mean values based on fasting status is likely less important clinically than longitudinal changes over time or even than test-retest variation.

Although studies on nonfasting lipids generally assume that fasting cholesterol levels are the gold standard to which other testing strategies should be compared, research results in adult patients suggest that nonfasting lipid panels also predict, and might even better predict, cardiovascular disease. ${ }^{12,15}$ It is particularly noteworthy that nonfasting triglycerides in adult patients are a risk factor for future myocardial infarction and death, ${ }^{16}$ and that nonfasting triglycerides might actually better predict cardiovascular events in some populations do than fasting values. ${ }^{17}$ In children and young adults, fasting values continue to be used for epidemiologic research, 2,3,30-33 although the 

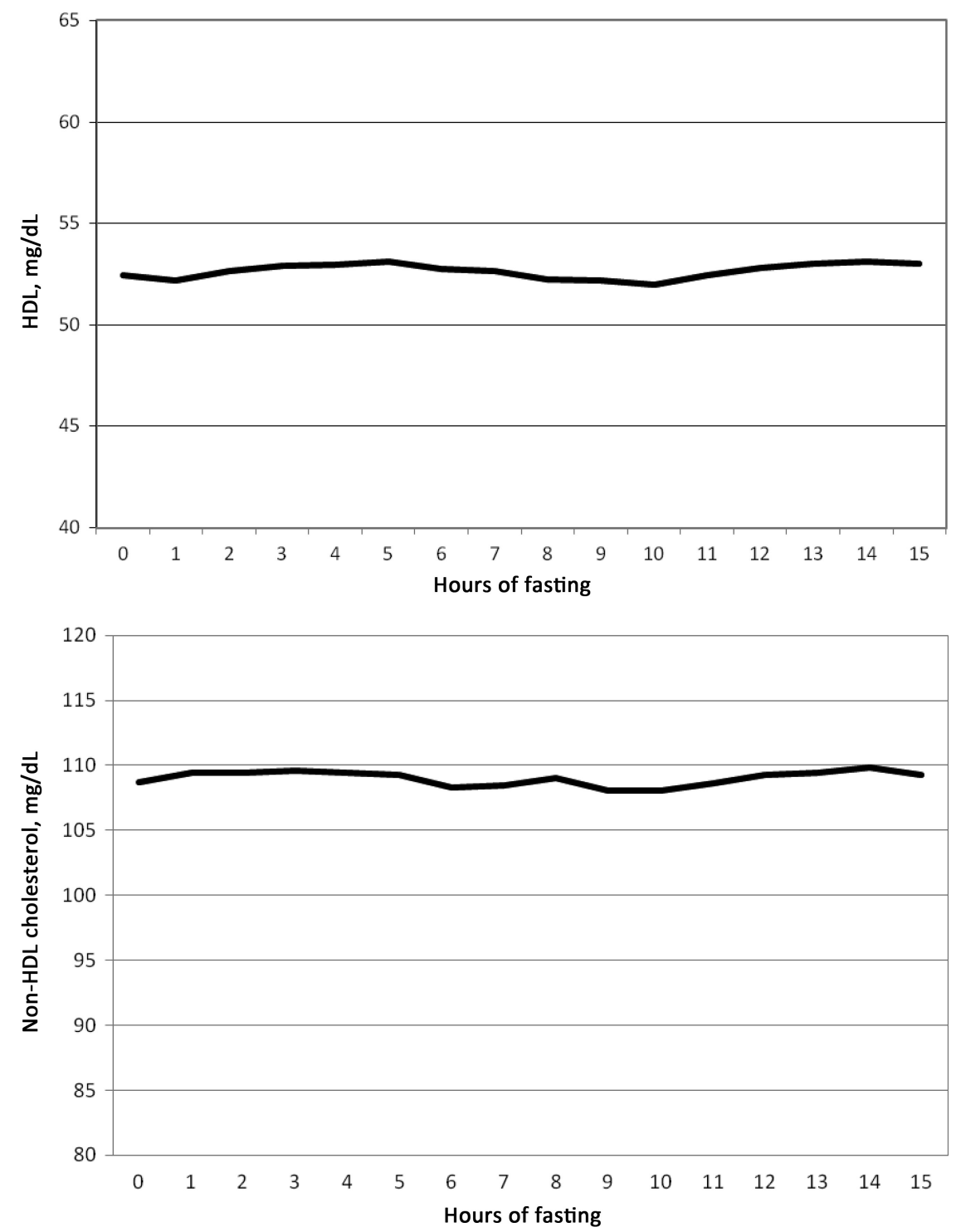

FIGURE 3

Predicted values of HDL and non-HDL cholesterol based on hours of fasting before testing.

TABLE 3 Effect of Fasting Time (in Hours) on TC, HDL, LDL, and Triglycerides According to Weight Status After Adjustment for Age, Race, and Gender

\begin{tabular}{|c|c|c|c|c|c|}
\hline & \multicolumn{2}{|c|}{ Healthy Weight } & \multicolumn{2}{|c|}{ Overweight or Obese } & \multirow{2}{*}{$\begin{array}{c}\text { Difference } \\
\qquad P^{a}\end{array}$} \\
\hline & $\beta$ & $\begin{array}{l}95 \% \text { Confidence } \\
\text { Interval }\end{array}$ & $\beta$ & $\begin{array}{c}\text { 95\% Confidence } \\
\text { Interval }\end{array}$ & \\
\hline Cholesterol & 0.089 & -0.102 to 0.279 & 0.292 & 0.029 to 0.555 & .163 \\
\hline $\mathrm{HDL}$ & 0.054 & -0.016 to 0.124 & 0.107 & 0.020 to 0.194 & .336 \\
\hline Non-HDL & 0.035 & -0.155 to 0.225 & 0.185 & -0.079 to 0.449 & .299 \\
\hline LDL & 0.360 & -0.054 to 0.775 & 0.688 & 0.224 to 1.152 & .223 \\
\hline Triǵlycerides & -0.970 & -1.705 to -0.234 & -0.717 & -1.726 to 0.292 & .656 \\
\hline
\end{tabular}

a $P$ value for the difference between coefficients in the healthy weight and overweight regressions.

degree to which fasting improves risk prediction in children is questionable. For example, Frontini et al analyzed the predictive values of non-HDL cholesterol of children in the Bogalusa Heart Study database. Non-HDL cholesterol does not change with fasting status, and Frontini et al determined that it predicted future cardiovascular events as well as other lipoprotein measurements. ${ }^{20}$

The major limitation of our research was that all analyses were conducted across a large sample and on a crosssectional basis. We were not able to analyze the cholesterol results from an individual child repeatedly after various periods of fasting. Although our research allows us to confidently demonstrate the population-level differences in cholesterol values at various periods of time after eating, we assume that some children will have greater or less dramatic differences in fasting and nonfasting values. For example, although not statistically different, values for obese children had a trend toward more dramatic lipid result changes with fasting. In addition, it is possible that there was a systematic difference within our sample between children who fasted and children who did not fast before testing. We did control for weight status, which should mitigate 1 risk for unmeasured systematic differences associated with which of the children fasted, but there might be others. A third limitation of our work was that all of our LDL cholesterol values were calculated values determined by use of the Freidewald equation used in the NHANES. ${ }^{11}$ Directly measured LDL values are increasingly being used in clinical laboratories, and studies comparing directly measured LDL to calculated LDL after various fasting times in children are warranted. However, in previous work with adult patients, directly measured and calculated fasting $L D L$ values were similar and equally predicted future cardiovascular events. ${ }^{34}$

The AAP currently recommends a fasting lipid panel on any child or adolescent with an increased risk of hyperlipidemia or other cardiovascular risk 
TABLE 4 Effect of Fasting Time on TC, HDL, LDL, and Triglycerides According to Age After Adjustment for Gender, Race, and BMI Percentile According to Age

\begin{tabular}{|c|c|c|c|c|c|c|c|c|c|c|}
\hline & \multicolumn{2}{|c|}{ Age 3-5 y } & \multicolumn{2}{|r|}{ Age 6-8 y } & \multicolumn{2}{|c|}{ Age 9-11 y } & \multicolumn{2}{|c|}{ Age $12-14$ y } & \multicolumn{2}{|c|}{ Age 15-17 y } \\
\hline & $\beta$ & $\begin{array}{l}\text { 95\% Confidence } \\
\text { Interval }\end{array}$ & $\beta$ & $\begin{array}{l}\text { 95\% Confidence } \\
\text { Interval }\end{array}$ & $\beta$ & $\begin{array}{l}\text { 95\% Confidence } \\
\text { Interval }\end{array}$ & $\beta$ & $\begin{array}{l}\text { 95\% Confidence } \\
\text { Interval }\end{array}$ & $\beta$ & $\begin{array}{c}\text { 95\% Confidence } \\
\text { Interval }\end{array}$ \\
\hline Cholesterol & 0.238 & -0.231 to 0.708 & 0.072 & -0.279 to 0.424 & $0.365^{a}$ & 0.057 to $0.673^{a}$ & 0.186 & -0.017 to 0.388 & 0.282 & -0.051 to 0.615 \\
\hline $\mathrm{HDL}$ & 0.034 & -0.142 to 0.210 & $0.162^{\mathrm{a}}$ & 0.018 to $0.306^{a}$ & $0.196^{a}$ & 0.066 to $0.325^{a}$ & $0.089^{a}$ & 0.000 to $0.178^{a}$ & -0.008 & -0.105 to 0.089 \\
\hline Non-HDL & 0.208 & -0.279 to 0.695 & -0.090 & -0.402 to 0.223 & 0.169 & -0.126 to 0.465 & 0.097 & -0.099 to 0.292 & 0.290 & -0.045 to 0.625 \\
\hline LDL & $0.618^{a}$ & 0.218 to $1.018^{a}$ & 0.265 & -0.276 to 0.805 & 0.640 & -0.067 to 1.346 & 0.717 & -0.234 to 1.668 & $1.240^{\mathrm{a}}$ & 0.129 to $2.351^{\mathrm{a}}$ \\
\hline Triglycerides & -0.480 & -1.815 to 0.855 & $-1.371^{a}$ & -2.496 to $-0.246^{a}$ & -0.711 & -1.561 to 0.140 & 0.038 & -1.856 to 1.932 & -0.451 & -2.244 to 1.343 \\
\hline
\end{tabular}

a Statistically significant effects.

factors. ${ }^{6}$ However, preparing for the fasting state makes screening recommendations more burdensome. In fact, although no formal cost analyses has been done, the fasting requirement likely makes the screening process more expensive because of the need for return office visits, increased transportation expenses, and missed work and/or school. This increased burden and cost are not only likely to undermine appropriate screening, but also potentially worsens the utility of screening in any formal cost analysis. Because research findings in other populations suggest that nonfasting lipid panels can predict cardiovascular events, and that the difference between fasting and nonfasting lipid panels in children is small and likely clinically insignificant, the risks of

\section{REFERENCES}

1. Ogden CL, Carroll MD, Curtin LR, Lamb MM, Flegal KM. Prevalence of high body mass index in US children and adolescents, 2007-2008. JAMA. 2010;303(3):242-249

2. Pletcher MJ, Bibbins-Domingo K, Liu K, et al. Nonoptimal lipids commonly present in young adults and coronary calcium later in life: the CARDIA (Coronary Artery Risk Development in Young Adults) study. Ann Intern Med. 2010;153(3):137-146

3. Davis PH, Dawson JD, Riley WA, Lauer RM. Carotid intimal-medial thickness is related to cardiovascular risk factors measured from childhood through middle age: the Muscatine Study. Circulation. 2001;104(23): 2815-2819

4. Mimoun E, Aggoun Y, Pousset M, et al. Association of arterial stiffness and endothelial dysfunction with metabolic syndrome in obese children. J Pediatr. 2008;153(1):65-70 missed screening or increased screening cost as a result of recommending fasting status raise questions regarding any benefits achieved.

\section{CONCLUSIONS}

Across a large, nationally representative sample of children, the levels of TC, HDL, non-HDL cholesterol, and LDL cholesterol vary minimally on the basis of fasting time. It is not known if these small differences in lipoprotein components consistently weaken or strengthen the usefulness of lipid values for the assessment of current health risks or prediction of future cardiovascular risks, but it is clear that testing regardless of fasting status would reduce barriers to screening. Therefore, future research with people in longitudinal samples is

5. Avis HJ, Vissers MN, Stein EA, et al. A systematic review and meta-analysis of statin therapy in children with familial hypercholesterolemia. Arterioscler Thromb Vasc Biol. 2007;27 (8):1803-1810

6. Daniels SR, Greer FR; American Academy of Pediatrics, Committee on Nutrition. Lipid screening and cardiovascular health in childhood. Pediatrics. 2008;122(1):198-208

7. Williams CL, Hayman LL, Daniels SR, et al. Cardiovascular health in childhood: a statement for health professionals from the committee on atherosclerosis, hypertension, and obesity in the young (AHOY) of the Council on Cardiovascular Disease in the Young, American Heart Association. CircuIation. 2002;106(1):143-160

8. Devaney BL, Gordon AR, Burghardt JA. Dietary intakes of students. Am J Clin Nutr. 1995;61(1 suppl):205S-212S warranted. If those results confirm our findings, professional societies might wish to reconsider their recommendations and encourage providers follow lipid screening guidelines at the point of care, regardless of fasting status.

\section{ACKNOWLEDGMENTS}

Dr Skinner was supported by a National Institutes of Health Building Interdisciplinary Careers in Women's Health award (K12-HD01441), and Dr Perrin was supported by a National Institutes of Health career development award (K23 HD051817).

We acknowledge the members of the Scientific Collaborative for Overweight and Obesity Prevention and Treatment at the University of North Carolina for their contributions to this work.

9. National Cholesterol Education Program (NCEP) Expert Panel on Detection, Evaluation, and Treatment of High Blood Cholesterol in Adults (Adult Treatment Panel III). Third Report of the National Cholesterol Education Program (NCEP) Expert Panel on Detection, Evaluation, and Treatment of High Blood Cholesterol in Adults (Adult Treatment Panel III) final report. Circulation. 2002;106(25):3143-3421

10. Rosenson RS. Lipoprotein classification; metabolism; and role in atherosclerosis. In: Basow DS, ed. UpToDate. Watham, MA: UpToDate; 2010

11. Friedewald WT, Levy RI, Fredrickson DS. Estimation of the concentration of low-density lipoprotein cholesterol in plasma, without use of the preparative ultracentrifuge. Clin Chem. 1972;18(6):499-502

12. Langsted A, Freiberg JJ, Nordestgaard BG. Fasting and nonfasting lipid levels: influ- 
ence of normal food intake on lipids, lipoproteins, apolipoproteins, and cardiovascular risk prediction. Circulation. 2008; 118(20):2047-2056

13. Nordestgaard BG, Benn M. Fasting and nonfasting LDL cholesterol: to measure or calculate? Clin Chem. 2009;55(5):845-847

14. Langsted A, Nordestgaard BG. Nonfasting lipids, lipoproteins, and apolipoproteins in individuals with and without diabetes: 58 434 individuals from the Copenhagen General Population Study. Clin Chem. 2011; 57(3):482-489

15. Mora S, Rifai N, Buring JE, Ridker PM. Fasting compared with nonfasting lipids and apolipoproteins for predicting incident cardiovascular events. Circulation. 2008; 118(10):993-1001

16. Nordestgaard BG, Benn M, Schnohr P, Tybjaerg-Hansen A. Nonfasting triglycerides and risk of myocardial infarction, ischemic heart disease, and death in men and women. JAMA. 2007;298(3):299-308

17. Bansal S, Buring JE, Rifai N, Mora S, Sacks FM, Ridker PM. Fasting compared with nonfasting triglycerides and risk of cardiovascular events in women. JAMA. 2007;298(3): 309-316

18. Ridker PM, Rifai N, Cook NR, Bradwin G, Buring JE. Non-HDL cholesterol, apolipoproteins A-I and B100, standard lipid measures, lipid ratios, and CRP as risk factors for cardiovascular disease in women. JAMA. 2005; 294(3):326-333

19. Srinivasan SR, Frontini MG, Xu J, Berenson GS. Utility of childhood non-high-density lipoprotein cholesterol levels in predicting adult dyslipidemia and other cardiovascular risks: the Bogalusa Heart Study. Pediatrics. 2006;118(1):201-206
20. Frontini MG, Srinivasan SR, Xu J, Tang R, Bond MG, Berenson GS. Usefulness of childhood non-high density lipoprotein cholesterol levels versus other lipoprotein measures in predicting adult subclinical atherosclerosis: the Bogalusa Heart Study. Pediatrics. 2008;121(5):924-929

21. Cui Y, Blumenthal RS, Flaws JA, et al. Nonhigh-density lipoprotein cholesterol level as a predictor of cardiovascular disease mortality. Arch Intern Med. 2001;161(11): 1413-1419

22. Craig SR, Amin RV, Russell DW, Paradise NF. Blood cholesterol screening influence of fasting state on cholesterol results and management decisions. J Gen Intern Med. 2000;15(6):395-399

23. Centers for Disease Control and Prevention. NHANES 2007-2008 public data general release file documentation. Available at: www. cdc.gov/nchs/nhanes/nhanes2007-2008/ generaldoc_e.htm. Accessed June 14, 2011

24. Centers for Disease Control and Prevention. A SAS program for the CDC growth charts. Available at: www.cdc.gov/nccdphp/dnpao/ growthcharts/resources/sas.htm. Accessed June 27, 2011

25. Centers for Disease Control and Prevention. National Health and Nutrition Examination Survey Laboratory Procedures Manual. Available at: www.cdc.gov/nchs/data/ nhanes/lab7-11.pdf. Accessed February 7, 2011

26. Cook S, Auinger P, Huang TT. Growth curves for cardio-metabolic risk factors in children and adolescents. J Pediatr. 2009;155: S6-S26

27. Freedman DS, Wang YC, Dietz WH, Xu JH, Srinivasan SR, Berenson GS. Changes and variability in high levels of low-density lipo- protein cholesterol among children. Pediatrics. 2010;126(2):266-273

28. Takahashi 0, Glasziou PP, Perera R, et al. Lipid re-screening: what is the best measure and interval? Heart. 2010;96(6): $448-452$

29. Glasziou PP, Irwig L, Heritier S, Simes RJ, Tonkin A; LIPID Study Investigators. Monitoring cholesterol levels: measurement error or true change? Ann Int Med. 2008;148(9): 656-661

30. Newman WP, Freedman DS, Voors AW, et al. Relation of serum-lipoprotein levels and systolic blood-pressure to early atherosclerosis: the Bogalusa Heart-Study. N Engl J Med. 1986;314(3):138-144

31. Berenson GS, Srinivasan SR, Bao WH, Newman WP, Tracy RE, Wattigney WA. Association between multiple cardiovascular risk factors and atherosclerosis in children and young adults. N Engl J Med. 1998;338(23): 1650-1656

32. Raitakari OT, Juonala M, Kahonen M, et al. Cardiovascular risk factors in childhood and carotid artery intima-media thickness in adulthood: the Cardiovascular Risk in Young Finns Study. JAMA. 2003;290(17): 2277-2283

33. Pencina MJ, D’Agostino RB Sr, Larson MG, Massaro JM, Vasan RS. Predicting the 30year risk of cardiovascular disease: the Framingham Heart Study. Circulation. 2009; 119(24):3078-3084

34. Mora S, Rifai N, Buring JE, Ridker PM. Comparison of LDL cholesterol concentrations by Friedewald calculation and direct measurement in relation to cardiovascular events in 27,331 women. Clin Chem. 2009; $55(5): 888-894$ 